San Jose State University

SJSU ScholarWorks

Master's Theses

Master's Theses and Graduate Research

Spring 2017

\title{
The Relationship Between Perceptions and Actual Use of Workplace Flexibility and Employee Engagement
}

Katherine Baer

San Jose State University

Follow this and additional works at: https://scholarworks.sjsu.edu/etd_theses

\section{Recommended Citation}

Baer, Katherine, "The Relationship Between Perceptions and Actual Use of Workplace Flexibility and Employee Engagement" (2017). Master's Theses. 4787.

DOI: https://doi.org/10.31979/etd.m8v8-gyv8

https://scholarworks.sjsu.edu/etd_theses/4787

This Thesis is brought to you for free and open access by the Master's Theses and Graduate Research at SJSU ScholarWorks. It has been accepted for inclusion in Master's Theses by an authorized administrator of SJSU ScholarWorks. For more information, please contact scholarworks@sjsu.edu. 
THE RELATIONSHIP BETWEEN PERCEPTIONS AND ACTUAL USE OF WORKPLACE FLEXIBILITY AND EMPLOYEE ENGAGEMENT

\author{
A Thesis \\ Presented to \\ The Faculty of the Department of Psychology \\ San José State University \\ In Partial Fulfillment \\ of the Requirements for the Degree \\ Master of Science
}

by

Katherine E. B. Baer

May 2017 
(C) 2017

Katherine E. B. Baer

ALL RIGHTS RESERVED 
The Designated Thesis Committee Approves the Thesis Titled

THE RELATIONSHIP BETWEEN PERCEPTIONS AND ACTUAL USE OF WORKPLACE FLEXIBILITY AND EMPLOYEE ENGAGEMENT

by Katherine E. B. Baer

APPROVED FOR THE DEPARTMENT OF PSYCHOLOGY

SAN JOSÉ STATE UNIVERSITY

May 2017

$\begin{array}{ll}\text { Dr. Howard Tokunaga } & \text { Department of Psychology } \\ \text { Dr. Megumi Hosoda } & \text { Department of Psychology } \\ \text { Janelle Tucker } & \text { Benefits Analyst, Tesla Motors }\end{array}$




\title{
ABSTRACT \\ THE RELATIONSHIP BETWEEN PERCEPTIONS AND ACTUAL USE OF WORKPLACE FLEXIBILITY AND EMPLOYEE ENGAGEMENT
}

\author{
By Katherine E. B. Baer
}

Previous research has identified both perceptions of the availability of flexible work arrangements and use of these arrangements as a predictor of engagement (Richman, Civian, Shannon, Hill, \& Brennan, 2008; Ten Brummelhuis, Bakker, Hetland, \& Keulemans, 2012). However, no studies have looked at the incremental effect that the use of flexible work arrangements have on engagement, above and beyond actual use. Very few studies have looked at how gender moderates the relationship between perceptions of flexible work arrangements and use of flexible work arrangements and engagement. The purpose of this study was to examine and compare the relationships between perceptions and actual use of flexible work arrangements and to examine the moderating effect of gender on these aforementioned relationships. One hundred and forty-nine survey results collected from employees at the Bay Area branch of large technology company revealed that actual use of flexibility did not have an effect on engagement, above and beyond that of perceptions of flexibility and engagement. Gender was found to moderate the relationship between actual use of flexible work arrangements and dedication, one of the three subscales of engagement assessed in the present study. It is suggested that organizations increase offerings of flexible work arrangements, and encourage employees to perceive the availability of these offerings, in order to increase the dedication of their employees. 


\section{ACKNOWLEDGMENTS}

First and foremost, I would like to thank my thesis committee for their support in this process. Thank you to Howard for guiding me from the very beginning and helping me take my original idea all the way to the final product. Thank you to Megumi for all of the insight you gave me along the way. This program has been an amazing experience and the lessons I learned in the classroom are things that I know I will use every day in my career.

Thank you to Janelle for your hard work and for and giving me a reader's perspective. You were a great mentor to me during my time at Tesla and I'm also grateful to you for being a member of my thesis committee.

Thank you also to my family and friends for your support. To my cohort: I am so glad that I got to experience this program with all of you. I'm lucky to have had a group of classmates who are also my friends. To my fiancé, Jason, you are the best in every way. Thank you for loving me, for giving me the space to work, and for putting up with takeout for dinner. Thank you to my friends for understanding how busy I have been and for offering your emotional support. And of course, thank you to my parents, who have been my \#1 academic cheerleaders from the very beginning. Your unconditional love has been everything to me. 


\section{TABLE OF CONTENTS}

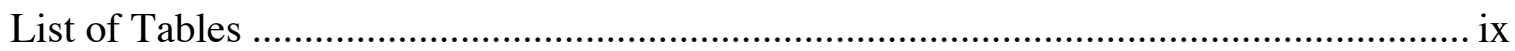

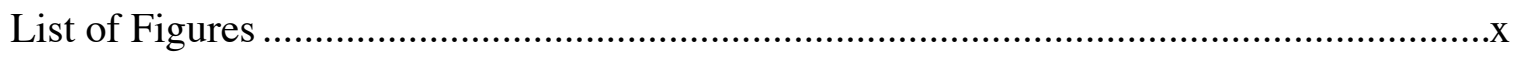

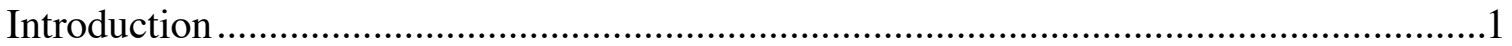

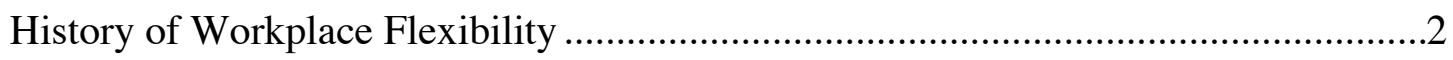

Qualitative Workplace Flexibility..........................................................................

Quantitative Workplace Flexibility.....................................................................

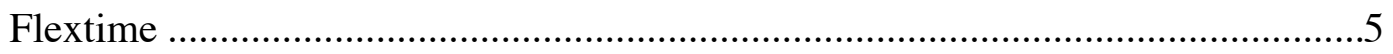

Occasional use of flexibility …………........................................................6

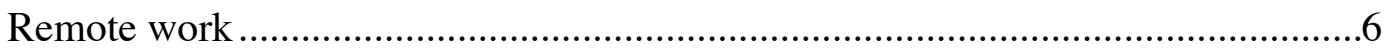

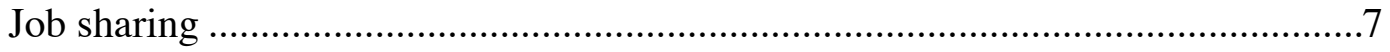

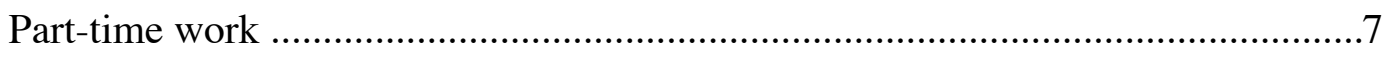

Perceived Availability of Flexibility versus Actual Use...............................................

Outcomes of Workplace Flexibility ………………….........................................

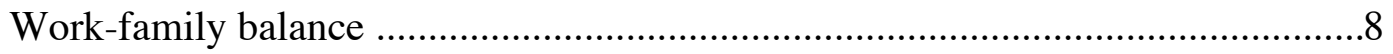

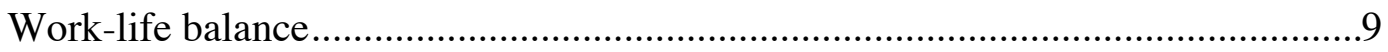

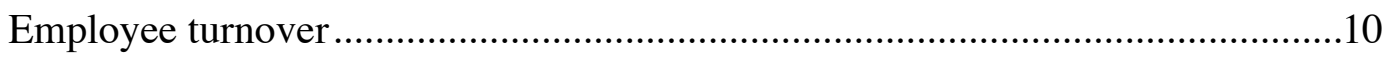

Physical and mental health..............................................................................10

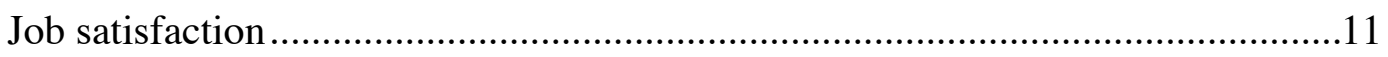

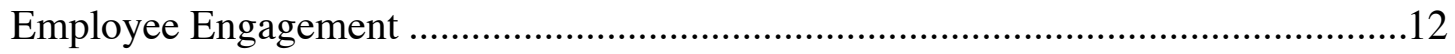

Predictors of engagement ..............................................................................13 


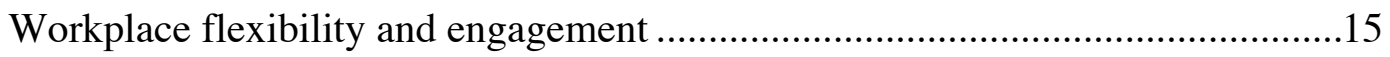

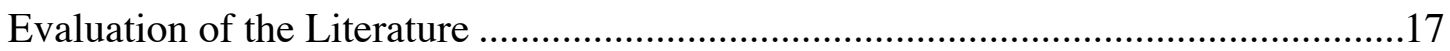

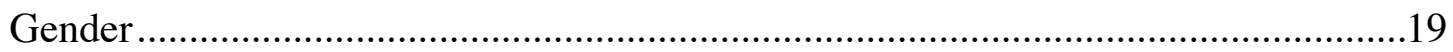

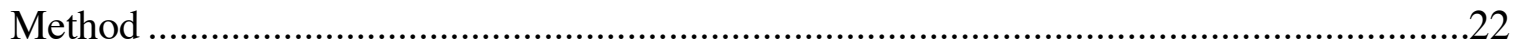

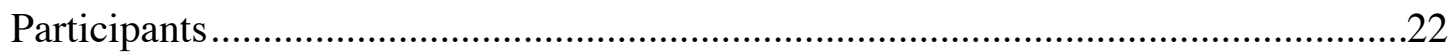

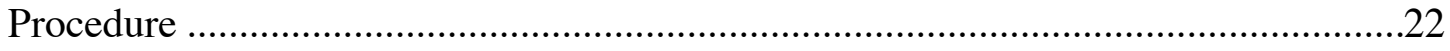

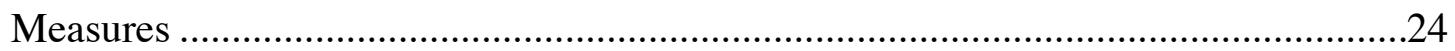

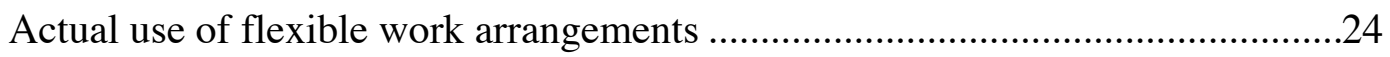

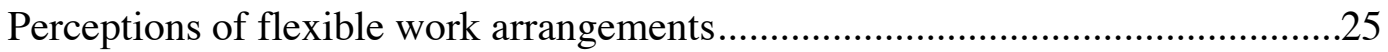

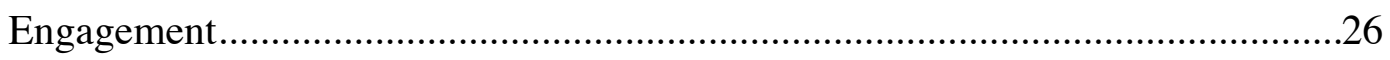

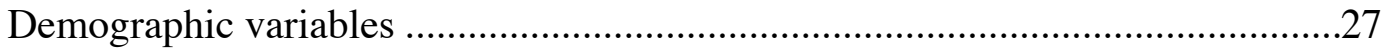

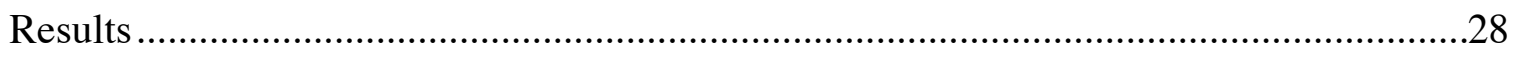

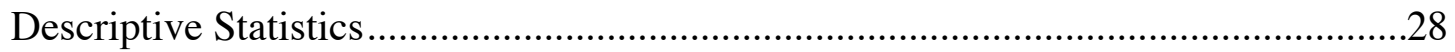

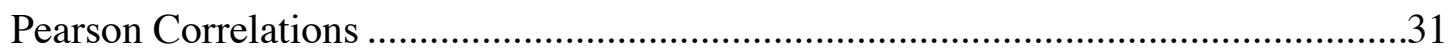

Test of Research Questions and Hypotheses ...............................................................31

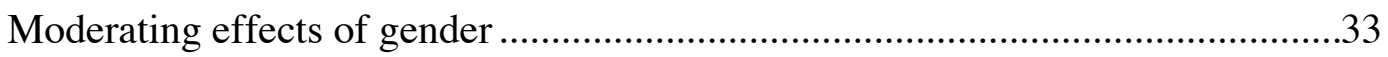

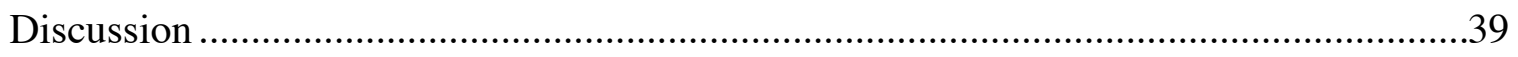

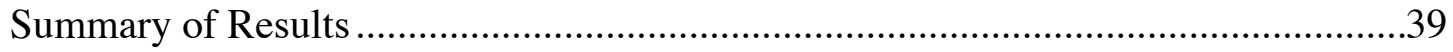

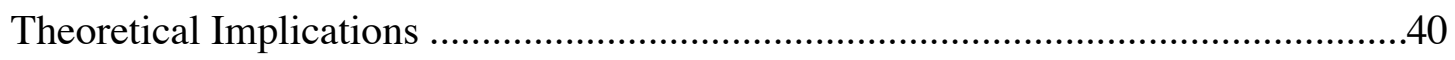

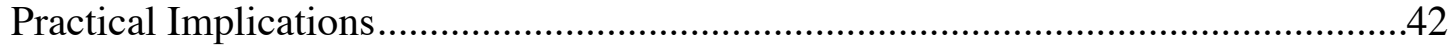

Strengths and Limitations of the Current Study .......................................................43

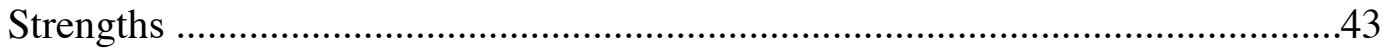


Limitations and future research

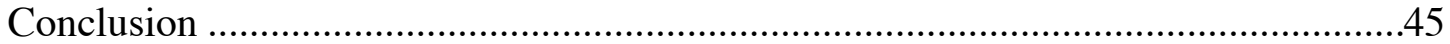

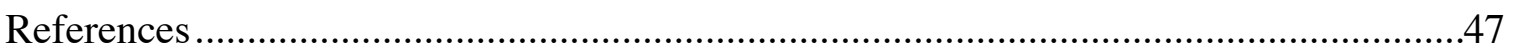




\section{LIST OF TABLES}

Table 1. Demographic characteristics of participants ................................................23

Table 2. Frequency and percentage of flexibility availability variables .........................28

Table 3. Means and standard deviations for flexibility use variables............................29

Table 4. Means, Standard Deviations, Pearson Correlations, and

Cronbach's Alphas

Table 5. Hierarchical Multiple Regression Correlation: Flexibility Perceptions and Use

Table 6. Hierarchical Multiple Regression Correlation: Moderating Effect of Gender on Flexibility Perceptions and Engagement

Table 7. Hierarchical Multiple Regression Correlation: Moderating Effect of Gender on Flexibility Use and Engagement 


\section{LIST OF FIGURES}

Figure 1. Moderating effect of gender on the relationship between flexibility

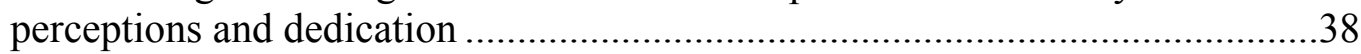




\section{Introduction}

Workplace flexibility is a concept that has been gaining attention in recent years as it has been positively correlated with organizational outcomes such as employee retention (Richman et al., 2008). Workplace flexibility can be defined as the ability of workers to make choices influencing when, where, and for how long they engage in work-related tasks (Hill, Erickson, Holmes, \& Ferris, 2010). At an individual level, workplace flexibility has been related to higher job satisfaction and reduced workplace stress (Kelliher \& Anderson, 2008; Masuda et al., 2012). Outside of work, workplace flexibility has been associated with decreased work interference with personal life (Hayman, 2009).

Some researchers have looked at the relationship between an employee's actual use of workplace flexibility and various outcomes (Masuda et al., 2012), whereas others have examined relationships involving perceptions of the availability of workplace flexibility (Hill, Hawkins, Ferris \& Weitzman, 2001). However, a gap exists in comparing the perceptions of availability of flexible work arrangements with the actual use of these arrangements in a single study. The purpose of the present study was to examine the relationship between both perceptions of the availability of workplace flexibility and the use of flexible work arrangements with employee engagement. Engagement was selected as a dependent variable because of its importance to organizations with such outcomes as increased job satisfaction, increased organizational commitment, reduced intentions to quit, and increase in organizational citizenship behaviors (Saks, 2006). The study also examined whether these relationships are moderated by gender. Gender was studied as a 
moderator because women have been shown to shoulder more of the responsibility in the home, including childcare, and therefore flexible work arrangements may be valued differently by working women who need flexibility at their jobs (Bureau of Labor Statistics, 2015).

\section{History of Workplace Flexibility}

The increasingly popular concept of workplace flexibility started as women began to enter the workforce in larger numbers, creating a need to accommodate the schedules of women with children (Hill, Jackson, \& Martinengo, 2006). Arrangements such as staggered work hours, which allow employees to select their start and end times, meant that mothers could drop their children off at school and leave work early to pick them up at the end of the school day while still working full-time hours. Arrangements such as these helped alleviate the burden of working parents by allowing them to control their schedules in a way that benefitted themselves and their families.

Organizations also benefited from flexible arrangements because they increased the retention of women in the workplace, leading to lower turnover (Hill et al., 2010). IBM was one of the first major corporations to see the benefit of flexible work arrangements, distributing surveys beginning in 1986 on Work and Life Issues to determine what kind of work/life balance issues employees were experiencing and how they could best be accommodated (Hill et al., 2006).

Currently employees face even greater time constraints that necessitate the ability for them to be flexible in order to balance their responsibilities. Employees are working a greater number of hours per week than ever before, with Gallup's Annual Work and 
Education Survey finding that U.S. employees report working an average of 47 hours per week, almost a full day more than the standard 9-5 Monday-Friday schedule (Saad, 2014). Many couples are dual-earners who rely on both incomes to support their families, while also caring for children and elderly parents in a rapidly aging society (Cullen, Hammer, Neal, \& Sinclair, 2009). With multiple responsibilities pulling individuals in a variety of directions, flexibility can alleviate burdens associated with having a traditional job with a set workplace and work hours.

\section{Qualitative Workplace Flexibility}

Workplace flexibility has been broken down into qualitative and quantitative flexibility, with the two types of flexibility serving different purposes in improving workplace and personal situations for employees. Qualitative workplace flexibility, also referred to as functional flexibility, can be defined as any workplace practice that makes the deployment of individual workers to particular tasks more adaptable by giving workers more control over the work that they do (Origo \& Pagani, 2008). Qualitative workplace flexibility consists of flexibility in the type of work, the ways of completing work, and the skills utilized in completing work. Qualitative workplace flexibility is not concerned with where or when employees work, but rather flexibility in the type of work employees do during their work hours. It is considered an example of a high performance workplace practice, which is a practice designed to give employees more control and personal responsibility over facets of their jobs, as well as a greater feeling of involvement in job-based decision making. According to Bauer (2004), the purpose of 
qualitative flexibility is to give more control to those doing the job with the hope that they will work harder and make better decisions.

Employee involvement, job rotation, work autonomy, teamwork, and use of multiple skills are forms of qualitative workplace flexibility. Employee involvement can be defined as "the exercise by employees of influence over how their work is organized and carried out" (Fenton-O'Creevy, 2001, p. 25). According to Huang (1999), job rotation can be defined as the "lateral transfer of employees among a number of different positions and tasks within jobs where each requires different skills and responsibilities" (p. 75). As a part of qualitative workplace flexibility, work autonomy is defined as the employee possessing considerable control over how to perform job-related tasks (Hackman \& Oldham, 1975). Teamwork as a flexible work arrangement can be defined as employee control over working in a group and how responsibilities are shared, thus giving employees the opportunity to modify how the work is completed to suit their needs or preferences. The possibility of using multiple skills is defined as the job requiring frequent development of new skills and possessing variety in its tasks (Origo \& Pagani, 2008). This gives employees the ability to select a job in which they will have the ability to continuously develop themselves.

\section{Quantitative Workplace Flexibility}

Quantitative workplace flexibility is a measurable type of flexible work arrangement that can be defined as control over when and where work is completed, as well as how much time is spent on work (Origo \& Pagani, 2008). Unlike qualitative workplace flexibility, which focuses on facets of the job, quantitative flexibility is not concerned 
with how the work is completed but simply the measurable aspects of the location of where job tasks are completed or the length of time or time of day in which work is performed. Quantitative workplace flexibility can either be part of an ongoing, formal work arrangement or it can be an informal arrangement that occurs on an ad-hoc basis. Quantitative workplace flexibility can consist of flextime, occasional use of flexibility, remote work, job sharing, and part time work.

Flextime. One type of quantitative flexibility is flexible time, or flextime, which refers to varying work arrangements regarding hours (Hill et al., 2008). Flextime may be broken down into having control over start and end times, staggered hours, compressed workweeks, and choice in the number of hours worked each week. The most common type of flextime is an employee having some control over when he or she starts and ends his or her workday. Generally, there are a certain number of hours and certain times in which the employee needs to work each day, but there is a window of time during which the employee can begin and end work. For example, Employee A works an average of 8 hours each day, has a start-time window of $8 \mathrm{AM}$ to $10 \mathrm{AM}$, is expected to be at work during the hours of 10AM to 4PM, and can leave work between 4PM to 6PM. Employee A may choose to start work at 8AM and leave at $4 \mathrm{PM}$ one day, but come in at 10AM and leave at $6 \mathrm{PM}$ the following day.

Another type of flextime is staggered hours, which refers to choosing non-standard hours to work each day in order to meet the demands of a non-traditional schedule. For example, Employee B may have a formal arrangement to work every day from 7AM to 
3PM, as opposed to her coworkers' 9-5 schedules, in order to pick up her daughter from school.

Compressed workweeks are a type of flextime in which a standard week of working hours is compressed into fewer days than the traditional workweek. For example, Employee C works a standard 40 hours per week, but works 10 hours per day Monday through Thursday instead of 8 hours per day Monday through Friday.

The final form of flextime is choice in the number of hours worked each week. This is much more common for salaried as opposed to hourly employees and involves the employee's ability to be flexible with the number of hours worked as opposed to having a set number of hours to be worked. The employee is responsible for the completion of assigned tasks and may be required to be available at certain times for meetings and appointments, but in general the employee has control over the fluctuation of hours.

Occasional use of flexibility. Another type of flexible work arrangement is occasional use of flexibility. Occasional use of flexibility is an employee's ability, on an occasional basis, to take a few hours off during the day, come in late, or leave early for such things as a doctor's appointment or a child's school event. Occasional use of flexibility is distinct from other forms of flextime because it is utilized infrequently and is generally not a regularly scheduled arrangement. Some employees may use occasional flexibility as they choose, whereas others may need to request this time off ahead of time and obtain permission from their supervisors.

Remote work. Remote work is an employee's ability to work someplace other than the office, such as from home, a hotel, or coffee shop. Telecommuting is a form of 
remote work in which technology is utilized to stay connected to the company and one's co-workers while working remotely. Remote work can consist of using a telephone to dial-in to a meeting or using a computer to login to the organization's intranet to use company email or inter-office instant messaging systems.

Job sharing. Job sharing is the ability of two or more employees to jointly share a full-time job by creating two part-time jobs (Mattis, 1990). The responsibilities of the job are divided between employees, sometimes by each employee doing a separate part of the job or by having employees share each task. Employees sharing a job can either work separate hours or work concurrently, and pay is usually based on one, full-time salary that is split between the two employees.

Part-time work. Similar to job sharing, part-time work is when an employee does not work a full workweek. In the United States, a part-time employee is anyone who works an average of fewer than 30 hours per week. Part-time work is usually a formal arrangement and the hours and parameters vary from job to job. It is a beneficial flexible option for employees who are enrolled in school, need to care for a family member, or have other commitments that do not allow them to work a standard workweek. It is also beneficial to employers who are looking to cut costs or have a need for an employee only at specific times.

\section{Perceived Availability of Flexibility versus Actual Use}

Quantitative workplace flexibility can be measured as perceptions of organizational flexibility or actual use of flexible work arrangements. The present study will focus exclusively on quantitative workplace flexibility, rather than qualitative, because of its 
ease of measurement and more existing research studies linking quantitative workplace flexibility to engagement. Perceptions of workplace flexibility can be defined as an employee's belief that flexible work arrangements are available at their current organization (Pitt-Catsouphes \& Matz-Costa, 2008). Actual use of flexibility is a measure of how often an employee makes use of flexible work arrangements and which arrangements he or she utilizes.

Perceived workplace flexibility is an important concept because researchers have shown that just the perceived ability to use flexible work arrangements when necessary or desired can have positive effects on employees (Hill et al., 2001; Richman et al., 2008). This is important for organizations because it shows that the positive impact associated with flexible work arrangements, such as greater work-family balance, extends to employees beyond those who actually utilize a flexible working schedule (Hill et al., 2001).

\section{Outcomes of Workplace Flexibility}

Workplace flexibility has numerous implications for employees. Researchers in the past have looked at outcomes of both perceived availability of flexible work arrangements and actual use of flexible work arrangements. Below several outcomes of perceived flexibility followed by actual use will be discussed: work-family balance, work-life balance, employee turnover, physical and mental health, and job satisfaction.

Work-family balance. Hill et al. (2001) conducted a study using data from the IBM Global Work and Life Issues Survey to look at the influence of perceived schedule flexibility on work-family balance. In this study, work-family balance was defined as 
"the degree to which an individual is able to simultaneously balance the temporal, emotional, and behavioral demands of both paid work and family responsibilities" (p. 49). The researchers found that employees who reported perceived schedule flexibility were able to work longer hours before reporting that their workload negatively impacted their work-family balance. Perceived flexibility was measured by asking employees how much flexibility they had in selecting when they worked, the location of where they worked, and scheduling what work they did, as well as whether they felt that the flexibility they had was sufficient to allow them to maintain an adequate work and personal family balance. The researchers found that a 1-point increase in flexibility on the 5-point scale was equivalent to reducing the employee's workload by 11 hours per week.

Work-life balance. Workplace flexibility has been found to enhance the relationship between one's work and personal lives (Hayman, 2009), leading to work-family enrichment (Carlson, Grzywacz, \& Kacmar, 2010). Hayman (2009) conducted a study with 710 participants in office-based jobs in New Zealand to assess the relationship between perceived usability of flexible work schedules and work-life balance. The researcher found that perceptions of usability of flexible work schedules were negatively related to one aspect of work-life balance: employee personal life interference with work. These results suggest that simply ensuring that employees feel that they are free to utilize flexible work schedules reduces instances of their personal lives interfering with work.

Other researchers have found both perceived flexibility (Hill, 2008; Carlson et al., 2010) and actual use of workplace flexibility (Masuda et al., 2012) to be related to 
reduced work-family conflict. Perceptions of workplace flexibility has been found to be associated with reduced work interference with personal life (Hayman, 2009) and increased work-life balance (Hill et al., 2001). In a study conducted by Masuda et al. (2012) of managers in different countries, a negative relationship was found between use of flexible work schedules and both time-based and strain-based work-family conflict. More specifically, when employees utilized the flexible work arrangements available at their organizations, they experienced less time-based and strain-based work-family conflict than their colleagues who did not use flexible work arrangements.

Employee turnover. Due to the extensive costs associated with employee turnover, organizations may be interested to know that workplace flexibility decreases turnover intentions. In a study conducted by Lee, Magnini, and Kim (2011) with hotel workers in South Korea, satisfaction with available schedule flexibility, or perceptions of sufficient available flexible work arrangements, was negatively related to turnover intentions.

Examining the effect of perceptions of flexible work schedules, Masuda et al. (2012) found a negative relationship between use of flexible work schedules and turnover intentions for managers. Use of flexible work schedules was measured by asking participants to answer yes or no to whether they were given the benefits of flextime, compressed workweeks, telecommuting and/or part-time work at their organization. The implication for both of these studies is that organizations that invest in flexible work offerings can reduce costly turnover.

Physical and mental health. Studies have showed that workplace flexibility has an impact on physical health and mental health outcomes, such as a reduction of stress and 
burnout. Hill et al. (2008) used a dataset from a large consulting company to assess if perceptions of flexible work arrangements could reduce stress and burnout. The authors found a negative relationship between perceived flexibility and both stress and burnout. Perceived flexibility was measured by asking employees to answer yes or no to whether they had the quantitative flexibility they needed at work.

A negative relationship between actual use of flexible work arrangements and stress was found in a study of employees at a software company in the UK (Kelliher \& Anderson, 2008). In this study, use of flexible work arrangements was measured by asking employees if they utilized remote work, flextime, staggered hours, and/or reduced work hours, how many days per week they used flexible work arrangements, whether the flexible work arrangements were formal or informal, and at whose discretion could the employee work flexibly. When looking at the relationship between flexible work arrangements and stress, the authors only looked at whether employees self-identified as flexible workers or not. The results of the Hill et al. (2008) and the Kelliher and Anderson (2008) studies suggest flexible work arrangements reduce stress whether employees simply feel flexibility is available to them if they need it or if it is actually utilized.

Job satisfaction. Workplace flexibility does not just have an impact on employees' behaviors but also impacts their attitudes. In the study by Masuda et al. (2012) that looked at the relationship between flexible work arrangements and manager outcomes, managers who reported more availability of flexible work arrangements were found to be more satisfied with their jobs than those who did not. Kelliher and Anderson (2008) 
looked at the relationship between flexible work arrangements and perceptions of job quality. They found that employees who used flexible work arrangements reported higher levels of job satisfaction than their colleagues who did not use flexible work arrangements.

In addition to job satisfaction, it is also important to look at the relationship between workplace flexibility and the similar construct of employee engagement. Job satisfaction refers to one's feelings and attitudes towards one's job, whereas employee engagement is a form of motivation that encourages absorption in one's work and a feeling of enthusiasm towards it. Job satisfaction can be related to employee engagement, but engagement has its own set of predictors and outcomes, which will be discussed in the next section.

\section{Employee Engagement}

Employee engagement is defined as an individual's involvement with as well as an enthusiasm for work (Harter, Schmidt, \& Hayes, 2002). According to Macey and Schneider (2008), engagement has multiple dimensions: engagement as a trait, engagement as a behavior, and engagement as a state. Engagement as a trait is comprised of the personality attributes of positive affectivity, conscientiousness, proactive personality, and autotelic personality. Autotelic personality refers to "people who engage in activities for their own sake rather than for specific gains or rewards" (Macey \& Schneider, 2008, p. 20). Employees who possess trait engagement have a natural tendency to experience work in a positive, active, and energetic way, behave adaptively, display effort, and go above and beyond in their jobs. Engagement as a behavior refers to 
the ability of an employee to adapt his or her behavior as needed to support organizational effectiveness. Engagement behaviors are often focused on initiating or fostering change, with a specific emphasis on proactive and personal initiative. Engagement as a state is a positive affect associated with the job and work setting that indicates feelings of persistence, vigor, energy, dedication, absorption, enthusiasm, alertness, and pride. Engagement as a state encompasses components of organizational commitment, job involvement, and the positive affectivity components of job satisfaction. For this study, I focused on measuring engagement as a state because it is the most likely to be influenced by job and organizational characteristics (Macey \& Schneider, 2008).

Employee engagement is meaningful to organizations because of its important implications for businesses. Employee engagement is a key business driver for organizational success. In an article on how to leverage employee engagement for competitive advantage, Lockwood (2007) states that high levels of engagement in domestic and global firms promote retention of talent, foster customer loyalty, and improve organizational performance and stakeholder value. Employee engagement has been found to be a stronger predictor of organizational performance than job satisfaction, employee commitment, and organizational citizenship behaviors (Markos \& Sridevi, 2010).

Predictors of engagement. Besides workplace flexibility, many other predictors related to organizational practices have been researched as predictors of employee engagement. Support is an important aspect as it relates to engagement: predictors of 
engagement include perceived organizational support (Ram \& Prabhakar 2011; Saks, 2006), perceived supervisory support (Ram \& Prabhakar, 2011), and supportive work life policies (Richman et al., 2008). Saks (2006) conducted a study of 102 employees in various jobs and organizations and found that perceived organizational support, defined as a belief that the organization for which the employees work values their contributions and cares about their well-being (Rhoades \& Eisenberg, 2002), positively predicted employees' engagement with both their jobs and the organizations for which they worked.

Ram and Prabhakar (2011) conducted a study of individuals working in the hotel industry in Jordan and found that both perceived organizational support and perceived supervisory support, defined as a belief that the employees' supervisors care about their contributions and well being, were positively related to engagement. Richman et al. (2008) found a positive relationship between engagement and supportive work-life policies, which was measured by employees self-reporting that they felt that their companies' policies were supportive of their personal/family life.

Other aspects of the job have also been found to be important for engagement. For example, Saks (2006) found a positive relationship between perceptions of procedural justice, defined as the perceived fairness of the means and processes used to determine the amount and distribution of resources, and engagement with the organization. This implies that when employees feel that the organization practices procedural justice, they feel a stronger emotional commitment to the organization. In Ram and Prabhakar's (2011) study, the researchers found a positive relationship between perceptions of 
procedural justice and employee engagement, implying that feelings of procedural justice lead to employees feeling more involved with and committed to their jobs and more passionate about their work.

Demerouti, Bakker, Nachreiner, and Schaufeli (2001) examined engagement as an outcome of job resources, which are defined as physical, psychological, social, or organizational aspects of the job that reduce job demands and the associated physiological and psychological costs of these demands, are functional in achieving work goals, and stimulate personal growth, learning, and development. They found that job resources were positively correlated with employee engagement such that employees who had access to a variety of job resources felt more engaged with their work than those who did not.

Workplace flexibility and engagement. Workplace flexibility can also serve as a job resource. Having the option to be flexible at work can reduce job demands by allowing employees to work where and when they desire, such as in the late evening in order to meet a deadline. Workplace flexibility can help employees achieve work goals by giving them more opportunity to align their work schedules with their non-work schedules. For example, a mother of a young child can better meet the work goal of being promoted if she can adapt her hours at her job to fit picking her daughter up at school into her schedule. Workplace flexibility can also stimulate personal growth, learning, and development by giving employees an opportunity to use the available flexibility for personal growth. For example, two employees might work compressed 
workweeks, Monday through Thursday, but on Fridays one employee takes college classes while the other employee does volunteer work.

Previous research has looked at multiple ways in which quantitative workplace flexibility is related to engagement. Some studies looked at perceptions of availability of flexible work arrangements, whereas others looked at actual use of flexible work arrangements by employees. Two studies found a positive relationship between perceptions of flexible work arrangements and engagement (Pitt-Catsouphes \& MatzCosta, 2008; Richman et al., 2008). Pitt-Catsouphes and Matz-Costa (2008) conducted a study using a large, multi-national data set representing 183,454 employees from 22 different companies. Perceptions of flexibility were measured by asking employees to answer yes or no to whether they felt they had the flexibility they needed at work. The researchers found that perceptions of having the flexibility needed at work was positively related to engagement, especially for employees who were ages 45 or older; no differences in engagement were found across the age groups for those not reporting to have access to the flexibility they needed at work. Although the researchers did not explain the reasoning for this result, it is possible that this is due to employees aged 45 and older having more family commitments than their younger colleagues.

Richman et al. (2008) conducted a study using survey data from a large, multinational company consisting of 103,478 employees. Perceived flexibility was measured by asking employees to answer yes or no to whether they had the flexibility they needed at work. After controlling for several personal, family, and job characteristics, the researchers found that perceived flexibility was positively related to engagement. 
Ten Brummelhuis et al. (2012) looked at actual use of flexibility using a sample of employees at a large telecommunications company in the Netherlands. Actual use of flexibility was measured by sending a daily questionnaire to assess use of remote access, working from home, use of email to facilitate work, and use of phone to facilitate work. The researchers found that on days when employees made use of flexible work arrangements, they reported higher levels of work engagement.

Pitt-Catsouphes and Matz-Costa (2008) looked at formal flexible work arrangements and occasional use of flexibility at three companies. They measured flexibility by asking participants if they participated in flexible work arrangements as part of a formal work arrangement, on an occasional ad hoc basis, or if they did not use flexible work arrangements. The researchers found that both formal and informal use of workplace flexibility was positively related to engagement. Furthermore, they found that this relationship was stronger for formal flexible arrangements than for occasional use. Employees who had a formal flexible work arrangement with their managers and the organization were the most engaged, followed by those utilizing informal flexible work arrangements on an ad-hoc basis with their managers' permissions, and those not utilizing any flexible work arrangements were the least engaged.

\section{Evaluation of the Literature}

The research conducted studying the relationship between flexible work arrangements and engagement shows a clear positive relationship between both perceptions of flexible work arrangements and use of flexible work arrangements and engagement. Of the literature reviewed, Richman et al. (2008) was the only study to look at both perceptions 
and use of flexible work arrangements in the same study, but they did not compare the two. Many employees may choose not to utilize flexible work arrangements because they prefer a standard, 9-5 schedule and/or the amenities offered to them at their office, but the fact that perceptions of workplace flexibility has been positively associated with engagement suggests that the impact of flexible work arrangements reaches beyond those who utilize them.

Employees who perceive flexible work arrangements as being available to them may feel engaged simply due to their availability because these arrangements are viewed as a display of caring from the organization. Previous research has shown that perceptions of the availability of flexible work arrangements are enough to increase engagement but has not looked at whether actual use of these arrangements has any impact above and beyond perceptions. Looking at this relationship has the potential to highlight the importance of creating perceptions of available work arrangements within organizations and to encourage organizations to consider all employees in policy changes regarding flexible work arrangements and not just those who utilize them. Including both perceptions and use of flexible work arrangements allows for testing the incremental value of actual use of flexible work arrangements above and beyond perceptions and allows both relationships to be studied within the same individual.

For my study, I fulfilled a gap that exists in the literature with perceptions and use of flexible work arrangements not being looked at within the same study. More specifically, the goal of this study was to see if use of flexible work arrangements has an effect above and beyond that of perceptions of flexible work arrangements alone. 
Another gap that this study addressed related to the measurement of engagement. The present study separated engagement into three dimensions: vigor, dedication, and absorption (Schaufeli, Bakker, \& Salanova, 2006). Instead of looking at engagement as a single construct, the present study recognized it as being made up of three dimensions that should be evaluated separately. In this study, perceptions and use of workplace flexibility were related separately to vigor, absorption, and dedication.

Research Question 1: Does a significant, positive relationship exist between actual use of flexible work arrangements and each dimension of employee engagement, above and beyond that of perceptions of the availability of flexible work arrangements?

There are factors that could moderate the relationships between perceptions of availability or the actual use of flexible work arrangements and engagement. One potential factor that could impact the strength of these relationships is the gender of the employee. Although previous research has looked at gender as impacting the strength of the relationship between flexible work arrangements and other outcomes, the moderating effect of gender on the relationship between perceptions and actual use of flexible work arrangements and engagement has not been studied. The next section discusses why gender was examined as a potential moderator in the present study.

\section{Gender}

Previous research has studied differences in how women and men view and utilize flexible work arrangements. In research conducted by Catalyst (2001), women valued workplace flexibility more highly than men and were more likely than men to report that 
they would like to use a variety of flexible work arrangements such as flextime, working from home/telecommuting, changing their schedules on an ad-hoc basis, and reduced work hours/part-time. One of the original goals in the development of flexible work arrangements was to retain women in the workforce and reduce work-family conflict women felt as a result of often being the main caregivers for their children (Hill et al., 2008). Even though women's roles in the workplace have evolved since the original development of these programs and women have joined the workforce in increasing numbers, a study by Bond, Thompson, Galinsky, and Prottas (2003) found that couples with children were more likely to prefer reduced work hours for women than for men. For women without children but who intend on having children, this relationship may still hold true because working for a company that allows flexibility could benefit them when they have children in the future.

Research has also shown how gender acts as a moderator for various psychological outcomes. For example, Carlson et al. (2009) looked at how gender might act as a moderator of the relationship between schedule flexibility and work family conflict. They found that the relationship between schedule flexibility and reduced work-family conflict was stronger for women than for men, suggesting that women benefited more from flexible working arrangements than men.

Scandura and Lankau (1997) conducted a study looking at the moderating effect of gender on the relationships between perceptions of flexible work arrangements and organizational commitment and job satisfaction. They found that gender moderated the relationship between perceptions of availability of flexible work arrangements and job 
satisfaction, and that the relationship was stronger for women than for men. Similarly, the relationship between perceptions of flexible work arrangements and organizational commitment was also moderated by gender. Men reported similar levels of organizational commitment regardless of whether they perceived the availability of flexible work arrangements at the organization, but women who perceived flexibility reported higher levels of organizational commitment than women who did not perceive flexibility. These findings imply flexible work arrangements matter less in terms of fostering organizational commitment to men than they do to women.

In the present study, I expected that the relationship between perceived availability of flexible work arrangements and actual use of flexible work arrangements and employee engagement would be moderated by gender. More specifically, it was hypothesized that the relationship between perceived availability and actual use of flexible work arrangements would be stronger for women and weaker for men.

Hypothesis 1: The positive relationship between perceptions of availability of flexible work arrangements and employee engagement will be moderated by gender and the relationship will be stronger for females than for males.

Hypothesis 2: The positive relationship between use of flexible work arrangements and employee engagement will be moderated by gender and the relationship will be stronger for females than for males. 


\section{Method}

\section{Participants}

Participants in this study included employees at a San Francisco Bay Area branch of a large technology company. A total of 172 employees provided voluntary responses to the survey that was emailed to them, with a response rate of $28.6 \%$. Participants with a large number of missing data were excluded, resulting in the final sample of 149 participants. The final sample for the analysis relating to gender was 148 due to a participant not reporting gender.

Table 1 describes demographic information of the participants. Participants consisted of 57 females and 91 males of working age, with the largest number of participants $(50 \%)$ being between the ages of 40-49 and the second largest number (36\%) being between the ages of 30-39. Participants were most likely to have been at their current jobs for 1-3 years (51\%), followed by 5-10 years (38\%). A fairly small percentage of participants (18.8\%) had children under the age of 5 and most (81.2\%) did not have children under the age of 5 .

\section{Procedure}

Data collection was facilitated by the Qualtrics online survey platform. All employees at a selected branch of the company were sent the survey link to their professional emails by an internal employee representative. The email contained a brief background of the researcher's education and professional interests, and a short introduction to the study. Those who chose to participate clicked the provided link to take the included survey. 
Table 1

Demographic Characteristics of Participants $(N=149)$

\begin{tabular}{|c|c|c|}
\hline Variable & $\%$ & $n$ \\
\hline \multicolumn{3}{|l|}{ Gender } \\
\hline Male & $61.1 \%$ & 91 \\
\hline Female & $38.3 \%$ & 57 \\
\hline Other & $0.7 \%$ & 1 \\
\hline \multicolumn{3}{|l|}{ Age } \\
\hline Less than 30 & $11.4 \%$ & 17 \\
\hline $30-39$ & $24.2 \%$ & 36 \\
\hline $40-49$ & $33.6 \%$ & 50 \\
\hline $50-59$ & $27.5 \%$ & 41 \\
\hline 60 or older & $3.4 \%$ & 5 \\
\hline \multicolumn{3}{|l|}{ Years at current company } \\
\hline Less than a year & $11.4 \%$ & 17 \\
\hline $1-3$ years & $34.2 \%$ & 51 \\
\hline $3-5$ years & $13.4 \%$ & 20 \\
\hline $5-10$ years & $25.5 \%$ & 38 \\
\hline $10-15$ years & $12.1 \%$ & 18 \\
\hline More than 15 years & $3.4 \%$ & 5 \\
\hline \multicolumn{3}{|l|}{ Children under the age of 5} \\
\hline Yes & $18.8 \%$ & 28 \\
\hline No & $81.2 \%$ & 121 \\
\hline
\end{tabular}


Those who clicked the survey link were brought to a page containing the consent form, which described the purpose of the study and contained contact information for the researcher and the department chair. This page also emphasized the voluntary and anonymous nature of the study. Participants indicated whether or not they consented to the study by clicking one of either two options: "I consent," which allowed participants to continue to the study, or "I do not consent," which routed participants to the end of the survey. Participants who consented to the study answered questions on their perceptions of the availability of flexible work arrangements within the context of their current jobs, their actual use of flexible work arrangements, engagement, and some demographic questions. During the survey, participants had the option to end the survey at any time by closing out of their web browsers.

\section{Measures}

Actual use of flexible work arrangements. Actual use of flexible work arrangements was measured by asking employees if they utilized seven types of flexible work arrangements regularly or occasionally: compressed workweeks, job sharing, parttime work, remote work, staggered hours, control over start and end times, and number of hours worked each week. Regular and occasional use was measured by separate questions to allow the researcher to separately assess regular and occasional use. Regular use was defined as once per week on a continual basis for job sharing, part-time work, remote work, and staggered hours. For compressed workweeks and control over number of hours worked each week, regular use was defined as at least one week per month since the items refer to use on a weekly basis as opposed to a daily basis. Occasional use was 
defined as once in a while, on an ad-hoc basis. Participants selected the option that best defined their use of each flexible work arrangement that they indicated as being available to them. The possible answers for use differed based on whether the flexible work arrangement was meant to be used daily or weekly. For example, the possible answers for use of compressed workweeks included "Never," "A Few Weeks Per Year," "One Week Per Month," "Every Other Week," and "Every Week." Each answer received a score of 1-5, with 1 indicating that the participants never used the flexible work arrangement and 5 being that they always used the arrangement. A total score for use was calculated by taking the sum of the answers to the questions.

Perceptions of flexible work arrangements. Perceptions of the availability of flexible work arrangements were measured by asking employees if they felt that seven types of flexible work arrangements were available to them, regardless of whether they actually utilized them. An example of a question measuring perceptions of availability of compressed workweeks is as follows: "Do you feel that the option to use compressed workweeks is available to you?" and possible answers were "Yes," "No," or "Not Sure." Each question also included a definition of the flexible work arrangements. Other flexible work arrangements that were measured are job sharing, part-time work, remote work, staggered hours, control over start and end times, and number of hours worked each week. A flexible perceptions score was created by taking the sum of the number of flexible work arrangements in which perceptions of availability was indicated; answers that indicated "not sure" were not counted. 
Engagement. The items came from the Utretcht Work Engagement Scale (UWES-9) developed by Schaufeli et al. (2006). This nine-item scale is a shortened version of the original Utrecht Work Engagement Scale (UWES-15) and measures engagement by asking participants to indicate their level of agreement with each item. Each of the three dimensions was measured with three questions on the scale.

For this scale, vigor was operationally defined as having a lot of energy, zest, and stamina when working. A sample item asked to measure vigor is "When I get up in the morning, I feel like going to work." The reliability of this subscale was .89, which indicates that this scale had good reliability. Dedication was defined as strongly identifying with one's work because it is experienced as meaningful, inspiring, and challenging. A sample item measuring dedication is "I am proud of the work that I do." The reliability of this subscale was .90 , which indicates that this scale had excellent reliability. Absorption was defined as being happily engrossed in one's work, feeling immersed by the work, having difficulty detaching from it, and feeling that time is flying by. A sample item measuring absorption is "I am immersed in my work." The reliability of this subscale was .52 , which indicates that this scale had poor reliability.

The three engagement subscales, vigor, absorption, and dedication were all measured using a seven-point Likert scale. For all of the questions measuring the subscales of engagement, possible responses included 1) strongly disagree, 2) disagree, 3) somewhat disagree, 4) neither agree nor disagree, 5) somewhat agree, 6) agree, and 7) strongly agree. The responses within each measure were averaged to create a composite score. 
Demographic variables. Participants were asked about four demographic variables:

their age, their gender, their length in their current job, and whether or not they had children under the age of 5. 


\section{Results}

\section{Descriptive Statistics}

Table 2 displays the percentage of employees who perceived the different flexible work arrangements as being available to them. Of the possible flexible work arrangements, the largest percentage of employees indicated that remote work arrangements $(85.2 \%)$, control over daily working hours $(81.2 \%)$, staggered hours (71.1\%), and control over number of hours worked each week $(61.7 \%)$ were available to them. A small number of employees indicated that compressed workweeks were available to them (20.8\%) and almost no one perceived part-time work (2.7\%) and job sharing (1.3\%) as being available to them.

Table 2

Frequency and Percentage of Flexibility Availability Variables $(N=149)$

\begin{tabular}{lcc} 
& $\%$ & $n$ \\
\hline Compressed workweeks & $20.8 \%$ & 31 \\
Job sharing & $1.3 \%$ & 2 \\
Part-time work & $2.7 \%$ & 4 \\
Remote work & $85.2 \%$ & 127 \\
Staggered hours & $71.1 \%$ & 106 \\
Control of daily working hours & $81.2 \%$ & 121 \\
Control of weekly working hours & $61.7 \%$ & 92 \\
\hline
\end{tabular}

Table 3 displays the means and standard deviations for use of the flexible work arrangement variables. When asked which flexible work arrangements they used, employees indicated at least occasional use of control over number of hours worked each week $(M=3.89)$, control over daily working hours $(M=3.50)$, staggered hours $(M=$ 
3.27), remote work $(M=3.26)$, and compressed workweeks $(M=3.07)$. This shows that employees took advantage of all of the flexible work arrangements that a majority of employees perceived as being available to them. Of the remaining flexible work arrangements, the small group of employees who perceived part-time work $(M=1.00)$ and job sharing $(M=1.00)$ as being available to them indicated they never used them.

Table 3

Means and Standard Deviations for Flexibility Use Variables $(N=149)$

\begin{tabular}{lcc} 
Variable & $M$ & $S D$ \\
\hline 1. Compressed workweeks & 3.07 & 1.16 \\
2. Job sharing & 1.00 & .00 \\
3. Part-time work & 1.00 & .00 \\
4. Remote work & 3.26 & 1.00 \\
5. Staggered hours & 3.27 & 1.26 \\
6. Control of daily working hours & 3.50 & 1.12 \\
7. Control of weekly working hours & 3.89 & 1.31 \\
\hline
\end{tabular}

Note: $1=$ never, 2 = a few weeks per year, $3=$ one week per month, $4=$ every other week, 5 = every week (for variables 1 and 7).

$1=$ never, 2 = once a month, $3=$ once a week, $4=$ several days a week, $5=$ every day (for variables $2,3,4,5$, and 6).

Table 4 displays the means and standard deviations of perceptions and use of flexibility, as well as for the three engagement subscales (vigor, dedication, and absorption). As seen in this table, of the three subscales that made up engagement, employees agreed most with the dedication items $(M=5.48, S D=1.20)$. This shows that employees felt dedicated to the organization, in that they felt strongly involved in their work and experienced a sense of significance, enthusiasm, inspiration, pride, and 
challenge. Employees also indicated fairly high agreement with the other engagement subscales, absorption $(M=5.39, S D=0.87)$, and vigor $(M=5.00, S D=1.23)$. This shows that employees were also absorbed in their work, in that they felt engrossed in their work and time passed quickly for them while working. Employees also indicated vigor, in that they felt high levels of energy and mental resilience while working and were willing to invest effort into their work. For flexibility, employees reported a mean score of 3.24 for perceptions of flexibility with 0 indicating that employees do not perceive any flexible work arrangements as available to them and 7 indicating that they perceive all listed flexible work arrangements as available to them. This suggests that employees perceived a moderate number of flexible work arrangements as available to them. For flexibility use, employees indicated a mean use score of 11.68 out of a total possible use score of 35 , which indicates fairly low overall use of flexible work arrangements by employees.

Table 4

Means, Standard Deviations, Pearson Correlations, and Cronbach's Alphas $(N=149)$

\begin{tabular}{llllllll}
\hline Variable & $M$ & $S D$ & 1 & 2 & 3 & 4 & 5 \\
\hline 1. Flex perceptions & 3.24 & 1.40 & & & & & \\
2. Flexibility use & 11.68 & 5.30 & $.82^{* *}$ & & & & \\
3. Vigor & 5.00 & 1.23 & .14 & .06 & $(.89)$ & & \\
4. Dedication & 5.48 & 1.20 & $.26^{* *}$ & .08 & $.78^{* *}$ & $(.90)$ & \\
5. Absorption & 5.39 & .87 & .08 & -.02 & $.45^{* *}$ & $.42^{* *}$ & $(.52)$ \\
\hline
\end{tabular}

Note. ${ }^{*} \mathrm{p}<.05, * * \mathrm{p}<.01$.

Reliability coefficients (Cronbach's alpha) are in parentheses along the diagonal. 


\section{Pearson Correlations}

As seen in Table 4, the three engagement subscales (vigor, dedication, and absorption) were highly correlated with each other. Additionally, flexibility perceptions were positively correlated with dedication $(r=.26, p<.01)$, indicating that the more flexible work arrangements employees perceived as being available to them, the more dedication they felt towards the company. On the other hand, flexibility use was not correlated with any of the engagement subscales, indicating that employees who made more use of flexible work arrangements were not any more engaged than their colleagues who did not make use of these arrangements. Flexibility perceptions was strongly correlated with flexibility use, such that employees who perceived greater availability of flexible work arrangements were more likely to make use of them $(r=.82, p<.01)$.

\section{Test of Research Questions and Hypotheses}

Research Question 1 asked whether a significant, positive relationship exists between actual use of flexible work arrangements and employee engagement, above and beyond that of perceptions of the availability of flexible work arrangements. Three hierarchical multiple regressions were run to test this research question, one for each of the engagement subscales. In the first step, flexibility perceptions was entered because it has previously been established as being related to engagement. In the second step, flexibility use was entered to test if its effects would go above and beyond that of flexibility perceptions.

As seen in Table 5, looking across these three analyses, in the first step of the analysis, flexibility perceptions accounted for $3.6 \%$ of the variance in dedication $\left(\mathrm{R}^{2}=\right.$ 
$.036, F(1,133)=4.97, p<.05)$. Flexibility perceptions did not account for any of the variance in vigor $\left(\mathrm{R}^{2}=.025, F(1,134)=3.42, p>.05\right)$ or absorption $\left(\mathrm{R}^{2}=.000, F(1,134)\right.$ $=.01, p>.05)$. This indicates that employees who perceived the availability of flexible work arrangements were more dedicated but not more absorbed or more vigorous than their colleagues who did not.

In the second step of the three analyses, the addition of flexibility did not significantly increase the amount of variance accounted for in vigor $\left(\Delta \mathrm{R}^{2}=.015, F(1,133)=2.12, p>\right.$ $.05)$, dedication $\left(\Delta \mathrm{R}^{2}=.016 F(1,132)=2.25, p>.05\right)$, or absorption $\left(\Delta \mathrm{R}^{2}=.00, F\right.$ $(1,133)=.07, p>.05)$. This shows that a positive relationship did not exist between flexibility use and vigor, dedication, and absorption above and beyond that of flexibility perceptions. This indicates that flexibility use did not account for any variance in engagement beyond what was accounted for by flexibility perceptions.

Table 5

Hierarchical Multiple Regression Correlation: Flexibility Perceptions and Use $(N=149)$ Vigor

\begin{tabular}{lcccc}
\hline Step and predictor variable & $R$ & $\beta$ & $R^{2}$ & $\Delta R^{2}$ \\
\hline Step 1 Flexibility Perceptions & .158 & .158 & .025 & .025 \\
Step 2 Flexibility Use & .200 & -.217 & .040 & .015 \\
\hline
\end{tabular}

Dedication

\begin{tabular}{lcccl}
\hline Step and predictor variable & $R$ & $\beta$ & $R^{2}$ & $\Delta R^{2}$ \\
\hline Step 1 Flexibility Perceptions & .190 & $.190^{*}$ & $.036^{*}$ & $.036^{*}$ \\
Step 2 Flexibility Use & .228 & -.224 & .052 & .016 \\
\hline
\end{tabular}

\begin{tabular}{lcccc} 
Absorption & $R$ & $\beta$ & $R^{2}$ & $\Delta R^{2}$ \\
\hline Step and predictor variable & .009 & -.009 & .000 & .000 \\
\hline Step 1 Flexibility Perceptions & .025 & -.040 & .001 & .001 \\
Step 2 Flexibility Use & &
\end{tabular}
Note. ${ }^{*} \mathrm{p}<.05,{ }^{* *} \mathrm{p}<.01$. 
Moderating effects of gender. Hypothesis 1 (H1) stated that gender would moderate the relationship between perceptions of availability of flexible work arrangements and employee engagement, such that the relationship between perceptions of availability of flexible work arrangements and employee engagement would be stronger for females than for males.

Three hierarchical multiple regressions were conducted to test $\mathrm{H} 1$, one for each of the three subscales of engagement. In the first step of these analyses, flexibility perceptions was entered because it has previously been established as being related to engagement. In the second step, gender was entered. In the third step, the perceptions by gender crossproduct was entered to test the moderating effect of gender on the relationship between flexibility perceptions and engagement.

Looking across these three analyses, the first step of flexibility perceptions was significant only for dedication but not for vigor $\left(\mathrm{R}^{2}=.019, F(1,146)=2.79, p>.05\right)$ or absorption $\left(\mathrm{R}^{2}=.075, F(1,146)=.82, p>.05\right)$. Flexibility perceptions accounted for $6.5 \%$ of the variance in dedication $\left(\mathrm{R}^{2}=.065, F(1,145)=10.04, p<.01\right)$. This shows that employee flexibility perceptions was related to dedication, in that employees who felt that more flexible work arrangements were available to them were more likely to be dedicated toward their work. 
Table 6

Hierarchical Multiple Regression Correlation: Moderating Effect of Gender on

Flexibility Perceptions and Engagement $(N=148)$

Vigor

\begin{tabular}{lcccc}
\hline Predictor variable & $R$ & $\beta$ & $R^{2}$ & $\Delta R^{2}$ \\
\hline Step 1 Flexibility Perceptions & .137 & .137 & .019 & .019 \\
Step 2 Gender & .170 & .101 & .029 & .010 \\
Step 3 Gender x Flex Perceptions & .191 & -.344 & .037 & .008 \\
\hline
\end{tabular}

Dedication

\begin{tabular}{lcccl}
\hline Predictor variable & $R$ & $\beta$ & $R^{2}$ & $\Delta R^{2}$ \\
\hline Step 1 Flexibility Perceptions & .254 & $.254^{* *}$ & $.065^{* *}$ & $.065^{* *}$ \\
Step 2 Gender & .268 & .085 & $.072^{* *}$ & .007 \\
Step 3 Gender x Flex Perceptions & .283 & -.354 & $.080^{* *}$ & .008 \\
\hline
\end{tabular}

Absorption

\begin{tabular}{lcccc}
\hline Predictor variable & $R$ & $\beta$ & $R^{2}$ & $\Delta R^{2}$ \\
\hline Step 1 Flexibility Perceptions & .075 & .075 & .006 & .006 \\
Step 2 Gender & .082 & -.033 & .007 & .001 \\
Step 3 Gender x Flex Perceptions & .116 & .324 & .013 & .007 \\
\hline
\end{tabular}

Note. $* \mathrm{p}<.05, * * \mathrm{p}<.01$.

For the second step of the three analyses, the addition of gender was not a significant predictor of vigor $\left(\Delta \mathrm{R}^{2}=.01, F(1,145)=1.51, p>.05\right)$, dedication $\left(\Delta \mathrm{R}^{2}=.01, F(1,144)\right.$

$=1.11, p>.05)$, or absorption $\left(\Delta \mathrm{R}^{2}=.00, F(1,145)=.15, p>.05\right)$. This result suggests that neither male nor female employees were more vigorous towards their jobs, dedicated to the organization, or absorbed in their work than the other gender.

For the third step of the analyses, the addition of the perceptions by gender crossproduct did not account for a significant amount of variance above and beyond the direct effects of flexibility perceptions and gender for vigor $\left(\Delta \mathrm{R}^{2}=.008, F(1,144)=\right.$ $1.15, p>.05)$, dedication $\left(\Delta \mathrm{R}^{2}=.008, F(1,143)=1.28, p>.05\right)$, or absorption $\left(\Delta \mathrm{R}^{2}=\right.$ $.007, F(1,144)=.99, p>.05)$. This result shows that the relationship between flexibility perceptions and vigor, absorption, and dedication was not stronger for males or for 
females. These findings do not support H1, in that the relationship between flexibility perceptions and engagement was not stronger for females than for males.

Hypothesis $2(\mathrm{H} 2)$ stated that gender would moderate the relationship between use of flexible work arrangements and employee engagement, such that the relationship between use of flexible work arrangements and employee engagement would be stronger for females than for males. To test $\mathrm{H} 2$, three hierarchical multiple regressions were conducted to test the moderating effect of gender on the relationship between use of flexible work arrangements and the three engagement subscales. As shown in Table 7, flexibility use was entered into the first step as a control variable because previous research has already found a positive relationship between use of flexible work arrangements and engagement and it has been used as a control variable in other research. Gender was entered into the second step and the actual use by gender crossproduct was entered into the third step to test the moderating effect of gender on the relationship between use of flexible work arrangements and engagement. 
Table 7

Hierarchical Multiple Regression Correlation: Moderating Effect of Gender on Flexibility Use and Engagement $(N=149)$

Vigor

\begin{tabular}{lcccc}
\hline Step and predictor variable & $R$ & $\beta$ & $R^{2}$ & $\Delta R^{2}$ \\
\hline Step 1 Flexibility Use & .059 & .059 & .003 & .003 \\
Step 2 Gender & .104 & .085 & .011 & .007 \\
Step 3 Gender x Actual Use & .154 & -.428 & .024 & .013 \\
\hline
\end{tabular}

Dedication

\begin{tabular}{lcccc}
\hline Step and predictor variable & $R$ & $\beta$ & $R^{2}$ & $\Delta R^{2}$ \\
\hline Step 1 Flexibility Use & .085 & .085 & .007 & .007 \\
Step 2 Gender & .128 & .096 & .016 & .009 \\
Step 3 Gender x Actual Use & .207 & -.605 & .043 & .026 \\
\hline
\end{tabular}

\begin{tabular}{lcccc} 
Absorption & $R$ & $\beta$ & $R^{2}$ & $\Delta R^{2}$ \\
\hline Step and predictor variable & .019 & -.019 & .000 & .000 \\
Step 1 Flexibility Use & .025 & -.016 & .001 & .000 \\
Step 2 Gender & .044 & -.136 & .002 & .001 \\
Step 3 Gender x Actual Use & & &
\end{tabular}

Note. $* \mathrm{p}<.05, * * \mathrm{p}<.01$.

Looking across these three analyses, the first step of flexibility use was not significant for any of the three engagement subscales: vigor $\left(\mathrm{R}^{2}=.003, \mathrm{~F}(1,133)=.46, p>.05\right)$, dedication $\left(\mathrm{R}^{2}=.007, \mathrm{~F}(1,132)=.96, p>.05\right)$, or absorption $\left(\mathrm{R}^{2}=.000, \mathrm{~F}(1,133)=.05\right.$, $p>.05)$. Employees who indicated greater use of flexible work arrangements in their current jobs did not express more vigor, dedication, or absorption than their colleagues who indicated less use.

In the second step of the three analyses, gender was added and did not make a significant incremental contribution to vigor $\left(\Delta \mathrm{R}^{2}=.007, \mathrm{~F}(1,132)=0.97, p>.05\right)$, dedication $\left(\Delta \mathrm{R}^{2}=.009, \mathrm{~F}(1,131)=1.23, p>.05\right)$, or absorption $\left(\Delta \mathrm{R}^{2}=.000, \mathrm{~F}(1,132)\right.$ 
$=.04, p>.05$ ) above and beyond the effect of flexibility use. This indicates neither males nor females were more likely to be engaged than the other gender.

In the third step of the analyses, the moderating effect of gender accounted for an amount of variance above and beyond and the direct effects that approached significance for dedication $\left(\Delta \mathrm{R}^{2}=.026, \mathrm{~F}(1,130)=3.59, p=.06\right)$. For vigor $\left(\Delta \mathrm{R}^{2}=.013, \mathrm{~F}(1,131)=\right.$ $1.75, p>.05)$ and absorption $\left(\Delta \mathrm{R}^{2}=.001, \mathrm{~F}(1,131)=.17, p>.05\right)$, the interaction effect did not account for a significant amount of variable above and beyond the control variables. Therefore, only the moderating effect of gender was found for the relationship between use of flexible work arrangements and dedication.

Standard regression analyses were conducted to examine the moderating effect of gender on the relationship between flexibility use and dedication. Figure 1 illustrates that the relationship between flexibility use and dedication was stronger for females than for males. For males, there was almost no relationship between flexibility use and dedication. For females, there was a positive relationship between them. The results of this regression analysis partially supported $\mathrm{H} 2$. 


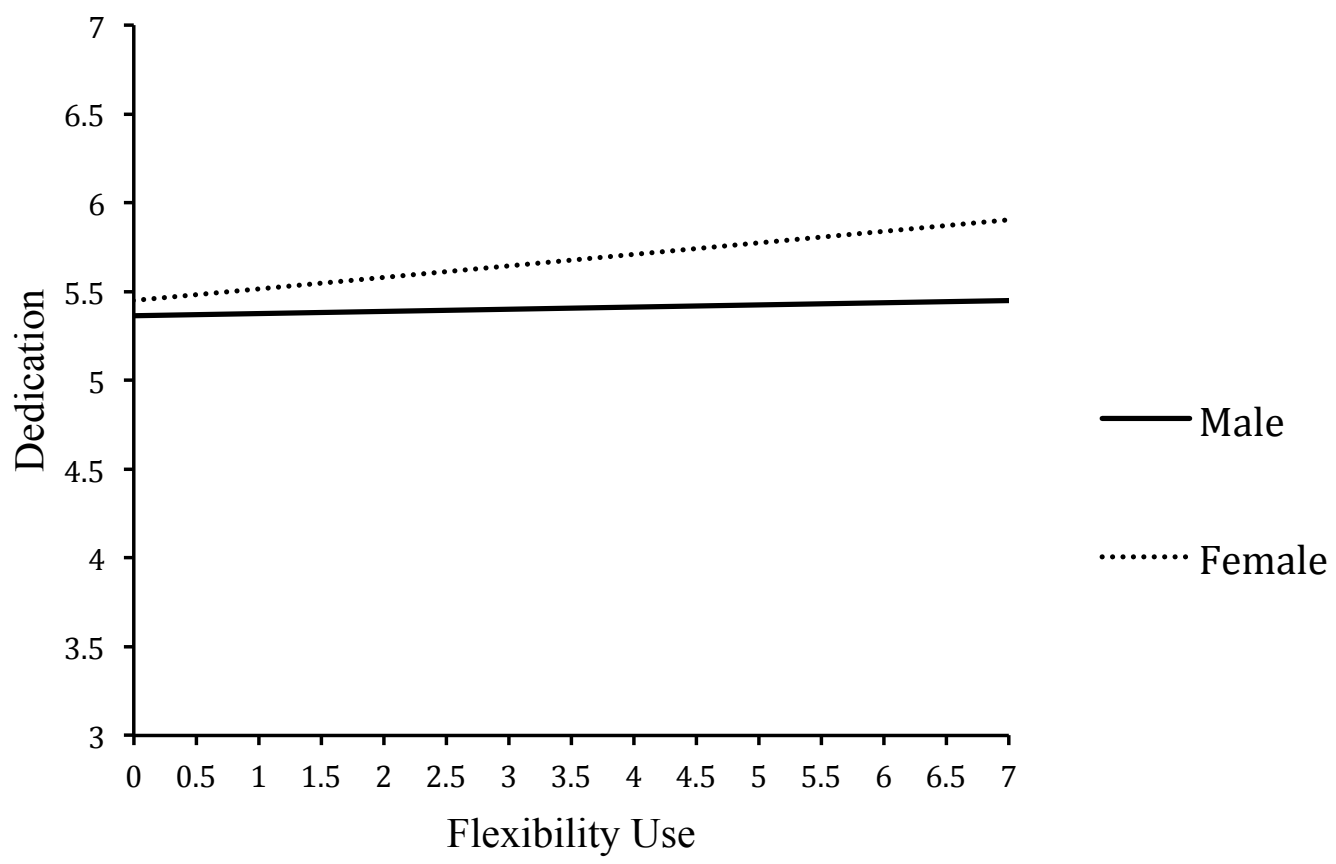

Figure 1. Moderating effect of gender on the relationship between flexibility perceptions and dedication 


\section{Discussion}

The goal of this study was to fill a gap in existing research regarding two relationships between flexible work arrangements and engagement: perceptions of availability of flexible work arrangements and the actual use of flexible work arrangements. Previous research has looked separately at the relationships between perceptions and use of flexible work arrangements and engagement but not together, as this study did. The second purpose was to examine whether the relationship between perceived and actual use of flexible work arrangements and engagement was stronger for females than for males. The following sections contain a summary of the study's findings, implications of the findings, strengths and limitations of the study, and directions for future research.

\section{Summary of Results}

The first research question asked whether a positive relationship existed between actual use of availability of flexible work arrangements and employee engagement, above and beyond that of use of perceptions. The results showed that a positive relationship existed between availability of flexible work arrangements and dedication, above and beyond that of use of flexible work arrangements; however, this relationship did not exist for vigor and absorption.

The first research hypothesis predicted that gender would moderate the relationship between perceptions of flexible work arrangements and engagement, in particular that this relationship would be stronger for females than for males. The results of the hierarchical MRC showed that gender did not moderate the relationship between 
perceptions of flexible work arrangements and vigor, dedication, or absorption. Thus, the hypothesis was not supported. These results indicated that the relationship between perceptions of flexible work arrangements and any of the three engagement subscales was not stronger for either males or females.

The second hypothesis predicted that gender would moderate the relationship between use of flexible work arrangements and engagement, in particular that this relationship would be stronger for females than for males. The results of the hierarchical MRC showed that gender moderated the relationship between use of flexible work arrangements and dedication, in that the relationship between use of flexible work arrangements and dedication was stronger for females than for males. Gender did not moderate the relationship between use of flexible work arrangements and either vigor or absorption, meaning that neither of those relationships was stronger for males or for females. Thus, the second research hypothesis was partially supported.

\section{Theoretical Implications}

This study provides a deeper understanding of the complex relationship between flexible work arrangements and engagement. These results are somewhat consistent with previous research but also show different outcomes in some cases. The positive relationship found between perceptions of flexible work arrangements and dedication is consistent with the findings of Pitt-Catsouphes and Matz-Costa (2008) and Richman et al. (2008), who both found a positive relationship between perceptions of flexible work arrangements and engagement. Both researchers, however, measured engagement differently than the present study. Pitt-Catsouphes and Matz-Costa (2008) acknowledged 
that engagement could be divided into three dimensions, which they viewed as cognitive connections to work, attachments to the company and the people, and a willingness to "go the extra mile," but they created a scale aimed at using the three dimensions to measure engagement as a whole. Richman et al. (2008) viewed employee engagement as being made up of three dimensions: affective commitment, discretionary effort, and alignment with the organization's goals. However, they used a scale that resulted in only one overall measurement of engagement. Based on the fact that the present study found a positive relationship only between perceptions of flexible work arrangements and dedication but not vigor or absorption, more research must be done into how engagement is measured across different studies to see what the most accurate method is and if engagement should even be measured as a single construct. It is possible that the present study found only a relationship between perceptions of flexible work arrangements and dedication because dedication is the best dimension by which to measure engagement. Another possibility is that flexible work arrangements really only impact dedication because employees naturally feel more dedicated to organizations that allow them to have a better balance in their lives, and that dedication should be looked as a separate concept and not as a part of engagement.

The fact that no relationship was found between use of flexible work arrangements and engagement contradicts the results found by Ten Brummelhuis et al. (2012). This might be due to the differences in measurement of engagement. Ten Brummelhuis et al. (2012) used a shortened, 5-item version of the Utrecht Engagement Scale but only assessed engagement as a single dimension. This result further suggests the need to 
investigate how engagement is measured. It is possible that if Ten Brummelhuis et al. (2012) measured engagement as the three separate dimensions outlined in the Utrecht Engagement Scale, the results would not be contradictory with the present study. One possible reason that actual use was not related to either of the three engagement dimensions in the present study, is that is that only the perception of the availability of flexible work arrangements is important to employees. Employees may feel more positive about their jobs if they know they can work flexibly if need be, but when actually utilizing the arrangements it does not increase engagement.

\section{Practical Implications}

A major implication that can be drawn from this study is that employees who perceive more flexible work arrangements as available to them are more likely to be dedicated to their organization than their colleagues. When considering the financial and logistical impact of offering flexible work arrangements within their organization, organizations should consider the fact that just perceiving the availability of flexible work arrangements is potentially impactful to all employees, not just utilizing those arrangements. Consistent with previous research by Lee, Magnini, and Kim (2011) and Masuda et al. (2012), offering employees flexible work arrangements results in positive organizational outcomes. Organizations that are seeking dedicated employees should consider offering various ways for their employees to work flexibly. The study found that the most utilized flexible work arrangements are control over hours worked during the day and each week, staggered hours, remote work, and compressed workweeks, 
respectively. When deciding which flexible work arrangements to offer, organizations may want to consider the most utilized arrangements found in this study.

Another important implication that can be drawn from this study is that utilizing flexible work arrangements is more impactful for women than for men. The study found that women were more likely to show dedication to the organization if utilizing flexible work arrangements than men utilizing the same arrangements. This finding is consistent with previous research that found that the relationship between workplace flexibility and various organizational outcomes is stronger for women than for men (Scandura \& Lankau, 1997; Carlson et al., 2009). It is suggested that this is due to the fact that women are likely to shoulder more of the responsibility of childcare. Organizations looking to attract more women, prevent costly turnover, or to appear family friendly should consider the benefits of having flexible work options and encouraging their employee to utilize them. In particular, given that previous research by Eaton (2003) has found that some companies offer flexible work arrangements but employees feel that they cannot make use of them, organizations should train supervisors to make sure that the organizational environment promotes use of these arrangements when desired and feasible.

\section{Strengths and Limitations of the Current Study}

Strengths. One strength of this study is the comparison between perceptions of workplace flexibility and use of flexibility and how those perceptions influence workplace engagement. Previous research has looked at either how perceptions of the availability of workplace flexibility or the actual use of workplace flexibility have influenced organizational outcomes, but did not compare the two. Creating a comparison 
between perceptions and use of flexibility gives organizations a more comprehensive understanding of how offering flexible work arrangements impacts employees.

Another conceptual strength of this study is that it breaks engagement down into the subscales of vigor, absorption, and dedication instead of looking at engagement as a single construct. This provides a better look at how flexible work arrangements impact employees. Organizations might be particularly interested in increasing one aspect of engagement, either what is most beneficial to the organization or what the employees at the organization are lacking and these organizations might prefer to see data that looks at the dimensions of engagement.

Finally, a strength of this study is its varied demographics for the information that is relevant for the study and potentially relevant for organizations. Gender was an important factor for this study due to the research question of gender acting as a moderator and given the gender gap that exists in the Bay Area tech industry, it was a strength that this study had $38.5 \%$ female respondents. Employees had spent a variety of lengths of time within the organization and $86 \%$ were between the ages of 30 and 50 , which encompassed the ages when most individuals have families and other outside commitments, like caring for an aging parent or involvement in a charitable organization, which makes workplace flexibility a key issue.

\section{Limitations and Future Research}

A limitation of the present study is the fact that the respondents were a fairly homogenous group in the fact that they worked at a technology organization in the San Francisco Bay Area. The organization employs mostly white-collar, highly skilled 
workers in corporate jobs such as sales, human resources, design, and engineering. The research cannot be broadly applied to work in all industries and job-types, particularly blue-collar work where the opportunity to work flexibly might look very different, if it is offered at all.

Future research should consider conducting a similar study in varying industries, such as auto and healthcare. The exact study may not be able to be replicated in every industry due to how flexibility in varying jobs differ, so future research studies should tailor the flexible work arrangements that they examine to the industry in which they are collecting data. For example, in the healthcare industry, employees may not be able to work from home but a form of flexibility could be job sharing which allows two employees to work part-time, both fulfilling one regularly full-time position. Also, as previously mentioned, it is important that future research examines how to properly measure engagement. Engagement is generally broken down into three subscales, but those subscales can differ and many studies use scales that contain the three subscales but only measure engagement as a whole. The fact that in the current study perceptions of flexible work arrangements was only related to dedication and not to vigor or absorption warrants future research to determine if all three subscales should be considered equal indicators of engagement.

\section{Conclusion}

With an ever-changing workforce that includes many individuals trying to balance their careers with familial responsibilities and outside interests, organizations that want to attract and retain top talent need comprehensive benefits to set them apart. Flexible 
workplace arrangements are attractive to employees and show an organization's commitment to the employee's life outside of the workplace. The growing availability of flexible work arrangements means that more people are able to enter the workforce.

Research should continue to assess how both perceptions and use of workplace flexibility contribute to employee engagement to give organizations a better understanding of how implementing flexible work arrangements impacts their employees and what type of employees they impact most. Organizations may think of flexible work arrangements as only influencing those who use them, but this study shows that just the perception of the availability of these arrangements leads to engagement, particularly dedication. Organizations should consider the importance of dedicated employees and what return on investment they might receive for offering flexible work arrangements to their employees. 


\section{References}

Bauer, T. (2004), High performance workplace practices and job satisfaction: Evidence from Europe, IZA Discussion Paper, No. 1265.

Bond, J. T., Thompson, C., Galinsky, E., \& Prottas, D. (2003). The 2002 national study of the changing workforce. New York: Families and Work Institute.

Bureau of Labor Statistics. (2015). American time use survey summary [Press release]. Retrieved from https://www.bls.gov/news.release/atus.nr0.htm

Carlson, D. S., Grzywacz, J. G., \& Michele Kacmar, K. (2010). The relationship of schedule flexibility and outcomes via the work-family interface. Journal of Managerial Psychology, 25, 330-355.

Catalyst (2001). The next generation: Today's professionals, tomorrow's leaders. New York: Catalyst

Cullen, J. C., Hammer, L. B., Neal, M. B., \& Sinclair, R. R. (2009). Development of a typology of dual-earner couples caring for children and aging parents. Journal of Family Issues, 30, 458-483.

Demerouti, E., Bakker, A. B., Nachreiner, F., \& Schaufeli, W. B. (2001). The job demands-resources model of burnout. Journal of Applied psychology, 86, 499512.

Eaton, S. (2003). If you can use them: Flexibility policies, organizational commitment, and perceived performance. Industrial Relations, 42, 145-167.

Fenton-O'Creevy, M. (2001). Employee involvement and the middle manager: saboteur or scapegoat? Human Resource Management Journal, 11, 24-40.

Hackman, J. R., \& Oldham, G. R. (1975). Development of the job diagnostic survey. Journal of Applied psychology, 60, 159-170.

Harter, J. K., Schmidt, F. L., \& Hayes, T. L. (2002). Business-unit-level relationship between employee satisfaction, employee engagement, and business outcomes: A meta-analysis. Journal of Applied Psychology, 87, 268-279.

Hayman, J. R. (2009). Flexible work arrangements: exploring the linkages between perceived usability of flexible work schedules and work/life balance. Community, Work \& Family, 12, 327-338. 
Hill, E. J., Erickson, J. J., Holmes, E. K., \& Ferris, M. (2010). Workplace flexibility, work hours, and work-life conflict: Finding an extra day or two. Journal of Family Psychology, 24, 349-358.

Hill, E. J., Hawkins, A. J., Ferris, M., \& Weitzman, M. (2001). Finding an extra day a week: The positive influence of perceived job flexibility on work and family life balance. Family Relations, 50, 49-58.

Hill, E. J., Jackson, A. D., \& Martinengo, G. (2006). Twenty years of work and family at International Business Machines Corporation. American Behavioral Scientist, 49, 1165-1183.

Hill, J. E., Jacob, J. I., Shannon, L. L., Brennan, R. T., Blanchard, V. L., \& Martinengo, G. (2008). Exploring the relationship of workplace flexibility, gender, and life stage to family-to-work conflict, and stress and burnout. Community, Work and Family, 11, 165-181.

Huang, H. J. (1999). Job rotation from the employees' point of view. Research and Practice in Human Resource Management, 7, 75-85.

Kelliher, C., \& Anderson, D. (2008). For better or for worse? An analysis of how flexible working practices influence employees' perceptions of job quality. The International Journal of Human Resource Management, 19, 419-431.

Lee, G., Magnini, V. P., \& Kim, B. P. (2011). Employee satisfaction with schedule flexibility: Psychological antecedents and consequences within the workplace. International Journal of Hospitality Management, 30, 22-30.

Lockwood, N. R. (2007). Leveraging employee engagement for competitive advantage. Society for Human Resource Management Research Quarterly, 1, 1-12.

Macey, W. H., \& Schneider, B. (2008). The meaning of employee engagement. Industrial and Organizational Psychology, 1, 3-30.

Markos, S., \& Sridevi, M. S., (2010). Employee engagement: The key to improving performance. International Journal of Business and Management, 5, 89-96.

Masuda, A. D., Poelmans, S. A., Allen, T. D., Spector, P. E., Lapierre, L. M., Cooper, C. L., ... \& Lu, L. (2012). Flexible work arrangements availability and their relationship with work-to-family conflict, job satisfaction, and turnover intentions: A comparison of three country clusters. Applied Psychology, 61, 1-29.

Mattis, M. C. (1990). New forms of flexible work arrangements for managers and professionals: Myths and realities. People and Strategy, 13, 133-146. 
Origo, F., \& Pagani, L. (2008). Workplace flexibility and job satisfaction: Some evidence from Europe. International Journal of Manpower, 29, 539-566.

Pitt-Catsouphes, M., \& Matz-Costa, C. (2008). The multi-generational workforce: Workplace flexibility and engagement. Community, Work and Family, 11, 215229.

Ram, P., \& Prabhakar, G. V. (2011). The role of employee engagement in work-related outcomes. Interdisciplinary Journal of Research in Business, 1, 47-61.

Rhoades, L., \& Eisenberger, R. (2002). Perceived organizational support: a review of the literature. Journal of Applied Psychology, 87, 698-714.

Richman, A. L., Civian, J. T., Shannon, L. L., Jeffrey Hill, E., \& Brennan, R. T. (2008). The relationship of perceived flexibility, supportive work-life policies, and use of formal flexible arrangements and occasional flexibility to employee engagement and expected retention. Community, Work and Family, 11, 183-197.

Saad, L. (2014, August 29). The "40-Hour" workweek is actually longer -- by seven hours. Gallup. Retrieved from http://www.gallup.com/poll/175286/hourworkweek-actually-longer-seven-hours.aspx

Saks, A. M. (2006). Antecedents and consequences of employee engagement. Journal of Managerial Psychology, 21, 600-619.

Schaufeli, W. B., Bakker, A. B., \& Salanova, M. (2006). The measurement of work engagement with a short questionnaire: A cross-national study. Educational and psychological measurement, 66, 701-716.

Scandura, T. A., \& Lankau, M. J. (1997). Relationships of gender, family responsibility and flexible work hours to organizational commitment and job satisfaction. Journal of organizational Behavior, 18, 377-391.

Ten Brummelhuis, L. L., Bakker, A. B., Hetland, J., \& Keulemans, L. (2012). Do new ways of working foster work engagement? Psicothema, 24, 113-120. 